\title{
Regarding "Embolization of Intracranial Dural Arteriovenous Fistulas Using PHIL Liquid Embolic Agent in 26 Patients: A Multicenter Study"
}

W e read the article by Lamin et al ${ }^{1}$ with considerable interest. They have highlighted their valuable experience with Precipitating Hydrophobic Injectable Liquid (PHIL; MicroVention, Tustin, California) embolic agent in the management of dural AVFs. We agree with their observations that the use of PHIL is safe and effective for endovascular management of dural AVFs, with outcomes comparable with those of Onyx (Covidien, Irvine, California).

A few points are worth mentioning. The advantages of PHIL over Onyx as they mentioned are the lack of any prior preparation, fewer beam-hardening artifacts, and less adhesiveness, leading to better forward penetration. ${ }^{1}$

Another advantage of PHIL over Onyx is seen when MR imaging is used on follow-up. Onyx causes susceptibility artifacts on gradient and susceptibility-weighted images, which are not seen with PHIL. ${ }^{2}$

Plug formation with PHIL is faster than with Onyx due to fewer layering effects, resulting in reduced fluoroscopy time and consequent radiation dose. ${ }^{2}$ There is minimal wastage with PHIL because it comes in a prefilled syringe in contrast to Onyx.

Failed embolization with subsequent requirement of an operation or combined endovascular and surgical management for dural AVFs has also been reported in previous studies. The au-

http://dx.doi.org/10.3174/ajnr.A5142 thors of this study did not experience this failure; however, it has been shown that Onyx forms a continuous smooth-surfaced column within vessels, while PHIL forms a rough-surfaced column interspersed with blood clots. Careful surgical handling of the vessel with low-voltage bipolar cautery to maintain vessel wall integrity is required with the PHIL embolic agent. ${ }^{2}$

We have made similar observations with PHIL at our institution and have found it to be an effective embolic agent in the management of intracranial AVFs as observed in the current study.

\section{REFERENCES}

1. Lamin S, Chew HS, Chavda S, et al. Embolization of intracranial dural arteriovenous fistulas using PHIL liquid embolic agent in 26 patients: a multicenter study. AJNR Am J Neuroradiol 2017;38: 127-31 CrossRef Medline

2. Koçer N, Hanımoğlu H, Batur Ş, et al. Preliminary experience with precipitating hydrophobic injectable liquid in brain arteriovenous malformations. Diagn Interv Radiol 2016;22:184-89 CrossRef Medline

V. Bhatia
A. Kumar
N. Khandelwal
Postgraduate Institute of Medical Education and Research
Chandigarh, India

